\title{
A Positive Dermcidin Expression Is an Unfavorable Prognostic Marker for Extramammary Paget's Disease
}

\author{
Shun Ohmori, Yu Sawada *, Natsuko Saito-Sasaki, Sayaka Sato, Yoko Minokawa, Hitomi Sugino, \\ Hikaru Nanamori, Kayo Yamamoto, Etsuko Okada (D) and Motonobu Nakamura
}

check for

updates

Citation: Ohmori, S.; Sawada, Y.; Saito-Sasaki, N.; Sato, S.; Minokawa, Y.; Sugino, H.; Nanamori, H.;

Yamamoto, K.; Okada, E.; Nakamura, M. A Positive Dermcidin Expression Is an Unfavorable Prognostic Marker for Extramammary Paget's Disease. Diagnostics 2021, 11, 1086. https:// doi.org/10.3390/diagnostics11061086

Academic Editor: Yasuhiro Sakai

Received: 8 May 2021

Accepted: 11 June 2021

Published: 14 June 2021

Publisher's Note: MDPI stays neutral with regard to jurisdictional claims in published maps and institutional affiliations.

Copyright: (c) 2021 by the authors. Licensee MDPI, Basel, Switzerland. This article is an open access article distributed under the terms and conditions of the Creative Commons Attribution (CC BY) license (https:/ / creativecommons.org/licenses/by/ $4.0 /)$.
Department of Dermatology, University of Occupational and Environmental Health, 1-1, Iseigaoka, Yahatanishi-Ku, Kitakyushu, Fukuoka 807-8555, Japan; oh-sh@med.uoeh-u.ac.jp (S.O.); natsuko-saito@med.uoeh-u.ac.jp (N.S.-S.); a0619gacha@gmail.com (S.S.); min.yo5.0628@gmail.com (Y.M.); hsugino@med.uoeh-u.ac.jp (H.S.); hikaru-n@med.uoeh-u.ac.jp (H.N.); kayohama@med.uoeh-u.ac.jp (K.Y.); e-okada@med.uoeh-u.ac.jp (E.O.); motonaka@med.uoeh-u.ac.jp (M.N.)

* Correspondence: long-ago@med.uoeh-u.ac.jp; Tel.: +81-093-691-7445

\begin{abstract}
Extramammary Paget's disease is recognized as an apocrine-origin cutaneous tumor and is localized in the intraepithelial skin lesion. However, its advanced form is intractable, and there is currently no therapeutic option with a satisfactory level of clinical outcome. Therefore, it is of great importance to identify a potential biomarker to estimate tumor advancement in extramammary Paget's disease. Dermcidin is an antimicrobial peptide derived from the eccrine gland and is identified as a biomarker in various malignancies. To investigate the potential of dermcidin in extramammary Paget's disease, we investigated dermcidin expression in tumors using the immunostaining technique. Although previous studies have reported that extramammary Paget's disease has no positive staining against dermcidin, 14 out of 60 patients showed positive staining of dermcidin in our study. To clarify the characteristics of positive dermcidin in extramammary Paget's disease, we investigated the clinical characteristics of positive dermcidin extramammary Paget's disease patients. Positive dermcidin patients showed a significantly high frequency of lymph node metastasis. We next investigated the impact of positive dermcidin on overall survival. Univariate analysis identified that positive dermcidin showed a significantly increased hazard ratio in overall survival, suggesting that dermcidin might be a prognostic factor for extramammary Paget's disease.
\end{abstract}

Keywords: extramammary Paget's disease; dermcidin; prognosis; lymph node metastasis; survival

\section{Introduction}

The skin is a large surface organ in the human body and is complicatedly organized with various unique cells and glands to adjust to external environmental changes [1-3]. Due to this unique characteristic of skin as a peripheral organ, various types of tumors, including malignancies, have the chance to emerge in it. In the early phase of tumor development, the tumor is localized in the skin, which can be adequately targeted through skin-focused local treatment, such as surgical resection [4]. However, once it progresses to an advanced form and causes distant organ metastasis, it is intractable due to the limited number of therapeutic options against these metastatic skin cancers [5]. Despite recent advancements in immune checkpoint and molecular targeted therapy, this therapeutic approach has still not reached a satisfactory level to obtain positive clinical outcomes [6].

The origin of extramammary Paget's disease is believed to be the apocrine glands. This is because the disease usually arises in the genital, perianal, and axillary regions, where the apocrine glands are located [7]. In agreement with this, previous histological studies have identified that extramammary Paget's disease showed positive immunoreactivity against gross cystic disease fluid protein (GCDFP)-15, carcinoembryonic antigen (CEA), and cytokeratin (CK) 7, all of which receive the same response from the apocrine glands [8]. In general, patients with extramammary Paget's disease have a good prognosis, with a 5-year 
overall survival of $75 \%$ to $95 \%$, because the disease is localized in the epidermis [4,9-12]. In contrast, dermal invasion is closely associated with lymph node metastasis and poor prognosis [8]. However, there is a limited number of biomarkers that can help toward the prognosis of extramammary Paget's disease.

A unique antimicrobial peptide was identified in 2001, i.e., dermcidin., which is constitutively produced by sweat glands. Additionally, an abundance of dermcidin was detected in sweat, showing a beneficial impact on antimicrobial action against microorganisms [13]. In contrast to its beneficial effect on the human body, however, dermcidin can also play an important role in the development of malignant tumors and other diseases. Based on this property of dermcidin, its usefulness as a biomarker for various diseases has been evaluated. Because extramammary Paget's disease is believed to be a malignant tumor derived from the apocrine glands, representing a negative expression of dermcidin in normal tissue, the possible role of dermcidin as a biomarker in patients with extramammary Paget's disease has not been investigated.

In this study, we investigated the potential of dermcidin as a biomarker for the prognosis of extramammary Paget's disease. We identified that there are two groups, dermcidin-positive and -negative extramammary Paget's disease. In addition, dermcidinpositive patients showed an unfavorable clinical behavior and a high frequency of lymph node metastasis. Our results suggest that dermcidin might be an independent prognostic factor in patients with extramammary Paget's disease.

\section{Materials and Methods}

\subsection{Patient Population}

In total, 60 patients who underwent surgery as an initial form of treatment for extramammary Paget's disease at the Department of Dermatology, University of Occupational and Environmental Health, were enrolled in this study from December 1979 to August 2017. The diagnosis was based on histopathological analysis carried out by two independent pathologists. Tissue specimens of the tumor were obtained from patients who underwent surgery at our institution. Because of the rarity of this malignant cutaneous tumor [14], it is sometimes difficult for a diagnosis of extramammary Paget's disease to be made, especially as it is hard to distinguish the disease from the pagetoid phenomenon. To exclude a pagetoid phenomenon, perianal extramammary Paget's disease was evaluated via GCDFP15+ and CK20- to determine the correctness of the diagnosis of extramammary Paget's disease. Patients were categorized according to the degree of dermcidin expression, age, sex, and the presence of depigmentation in the skin lesion.

\subsection{Immunostaining for Dermcidin}

Immunostaining was performed as reported previously $[15,16]$. In brief, immunochemical staining for dermcidin was conducted using two dermcidin monoclonal antibodies (mAbs) (A-20 and N-20) (Santa Cruz Biotechnology, Santa Cruz, CA, USA) on formalinfixed, paraffin-embedded specimens. In brief, specimens were cut into $4 \mu \mathrm{m}$ thick sections and then deparaffinized in xylene and dehydrated through graded alcohol solutions. Antigen retrieval was achieved via boiling in citrate buffer, $\mathrm{pH}$ 6.0, using a microwave treatment. All sections were treated with methanol containing $0.3 \% \mathrm{H}_{2} \mathrm{O}_{2}$ for 15 min to block endogenous peroxidase activity. Immunoglobulin $G$ was treated using normal rabbit serum (Nichirei, Tokyo, Japan) to avoid nonspecific antibody binding. After overnight incubation at $4{ }^{\circ} \mathrm{C}$ with mouse anti-dermcidin mAb (Lifespan BioSciences, Inc., Seattle, Washington, DC, USA), the sections were incubated with biotinylated rabbit-anti-mouse secondary antibody (Nichirei, Tokyo, Japan) followed by incubation in a streptavidin-peroxidase complex solution for $30 \mathrm{~min}$. Signals were generated via incubation with 3-amino-9-ethyl carbazole to visualize the immunostaining. The expression of dermcidin was classified into 2 groups: dermcidin-positive patients and dermcidin-negative patients. Negative dermcidin indicated absolutely no immunostaining reaction to anti-dermcidin antibody in both specific antibodies. 


\subsection{Statistical Analyses}

Fisher's exact test for unpaired data was used to analyze the association between dermcidin expression and various clinicopathologic factors. Univariate analyses of overall survival were conducted using the log-rank test, and Kaplan-Meier curves were generated. Overall survival was calculated from the date of first diagnosis to the date of death or latest contact with the patient. Univariate analysis was performed using the SPSS software (IBM Corp., Armonk, NY, USA). Kaplan-Meier survival analyses and Fisher's test were performed using GraphPad Prism 4.0. The senser on the survival curve means still alive or discontinuation of follow-up observation during this study period.

\subsection{Microarray Data Analysis}

For microarray data analysis, dermcidin mRNA expression in healthy subject tissues was obtained from a public data set deposited in the National Center for Biotechnology Information (NCBI) obtained from the Gene Expression Omnibus (GEO) database (GEO accession no. GDS3834) [17]. mRNA was extracted from human tissues, which were purchased from commercial vendors and subjected to microarray analysis.

\subsection{Study Approval}

Our retrospective study was approved by the Institutional Review Board at the University of Occupational and Environmental Health following the Declaration of Helsinki. Because this study was a retrospective cohort study, the opt-out method of obtaining informed consent was adopted, and informed consent was waived by the Institutional Review Board at the University of Occupational and Environmental Health.

\section{Results}

\subsection{The Finding of Dermcidin-Positive Extramammary Paget's Disease}

Dermcidin is produced by the eccrine glands, which are located in the skin. In agreement with this, microarray data set analysis showed that dermcidin expression was highest in the skin from healthy human tissues (Figure 1A). In addition, we confirmed that two antibodies against dermcidin showed a specific positive reaction to the eccrine glands (Figure 1B), suggesting that these antibodies reflect the positivity of dermcidin in the skin.

It has previously been reported that the expression of dermcidin was not identified in epithelial tumors, melanoma, and extramammary Paget's disease [18]. Although there were cases with no staining of dermcidin (Figure 1C), these antibodies showed that several patients diagnosed with extramammary Paget's disease had different expression patterns of dermcidin in the tumor, such as minuscule, average, and strong expression (Figure 1D). These unexpected results prompted us to investigate the characteristics of extramammary Paget's disease with or without dermcidin-positive reaction in further detail.

\subsection{The Different Characteristics of Extramammary Paget's Disease Depending on the Expression Degree of Dermcidin}

Although extramammary Paget's disease is usually characterized by no expression of dermcidin, as reported previously, we speculated that there were differences in clinical characteristics in extramammary Paget's disease between positive and negative expression of dermcidin.

To clarify this issue, we investigated the differences in age, sex, depigmentation as the manifestation of extramammary Paget's disease, and lymph node metastasis between dermcidin high- and low-expressing groups (Tables 1 and 2). Although there was no significant difference in age, sex, and depigmentation of the tumor, we noticed that the dermcidin-positive group showed a significantly high frequency of nodules and erosion of the tumor upon physical examination. In addition, the dermcidin-positive group also showed a high frequency of dermal invasion and lymph node metastasis. Dermal invasion cases enrolled in this study showed an unfavorable 5-year survival rate of $68.8 \%(p<0.0001)$ 
(Figure 2). These findings suggest that the positive expression of dermcidin might reflect the extension of tumor development.

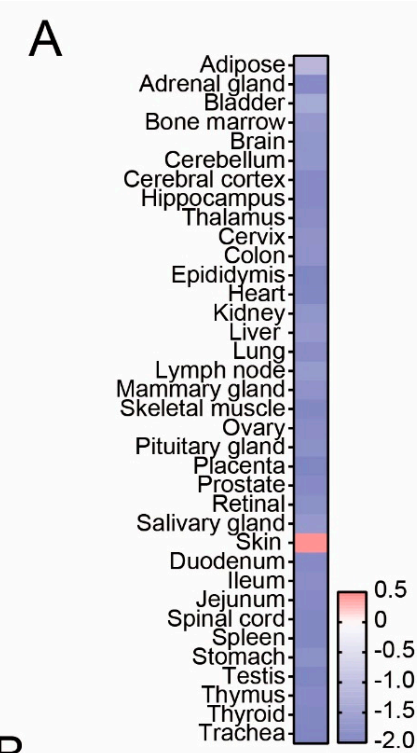

B

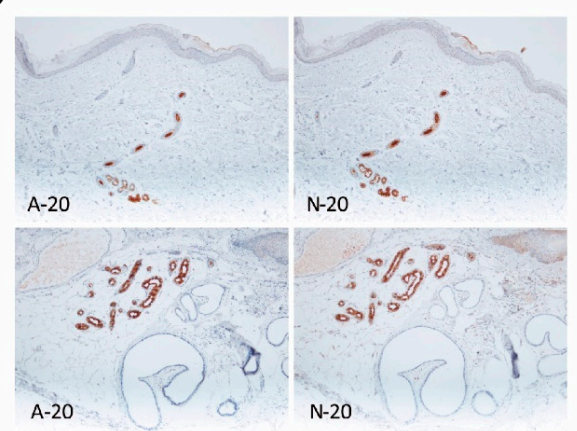

C

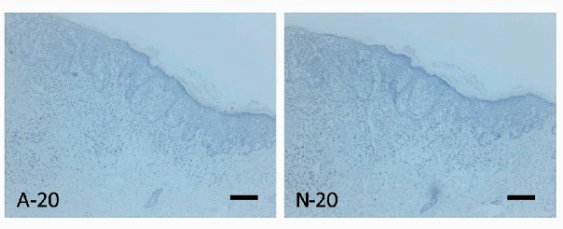

D
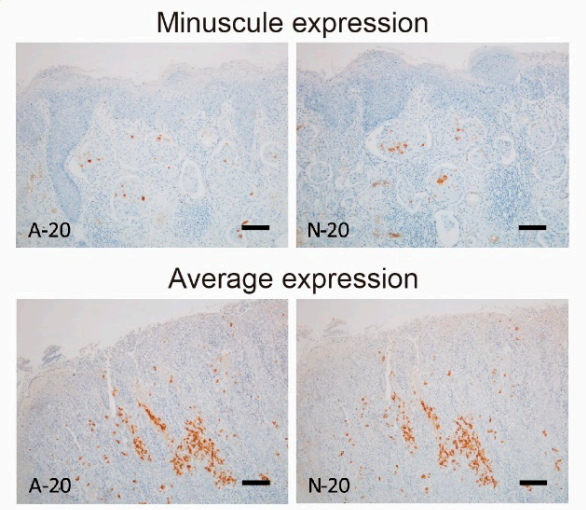

Strong expression

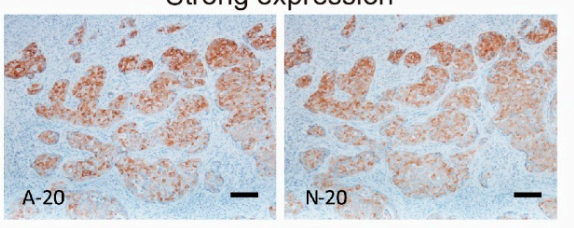

Figure 1. Dermcidin expression in healthy tissue and in the skin and positive staining in extramammary Paget's disease. (A) Microarray dataset analysis of dermcidin gene expression; (B) representative dermcidin immunostaining for eccrine glands in healthy subjects using two different immunostaining antibodies; $(\mathbf{C}, \mathbf{D})$ representative negative and $(\mathbf{C}, \mathbf{D})$ positive staining patterns of dermcidin were observed in extramammary Paget's disease tumor in both intraepithelial and dermal invasive tumors. (C) Scale bar: $100 \mu \mathrm{m}$; (D) scale bar: minuscule expression and average expression were determined at $100 \mu \mathrm{m}$, and strong expression was determined at $50 \mu \mathrm{m}$.

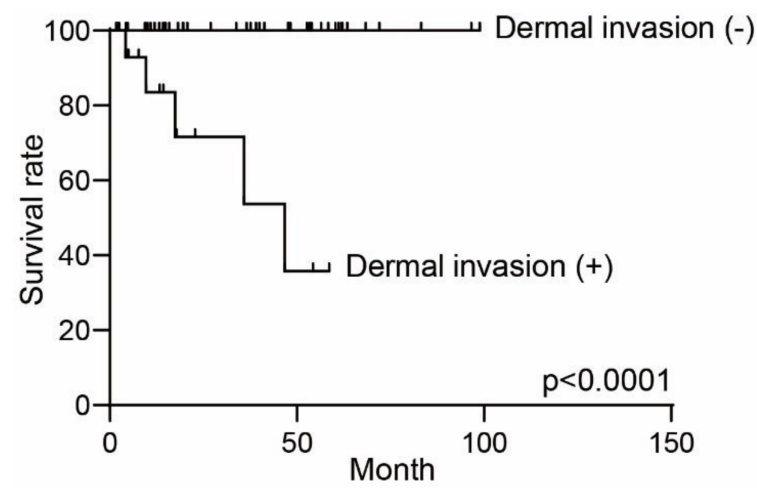

Figure 2. Difference of overall survival curve with or without dermal invasion in extramammary Paget's disease. The overall survival curves were drawn using the Kaplan-Meier method and were compared with the log-rank test. 
Table 1. Clinical characteristics of extramammary Paget's disease patients in this study.

\begin{tabular}{|c|c|c|}
\hline Variable & & Patients Number \\
\hline Total & & 60 \\
\hline \multicolumn{3}{|l|}{ Age } \\
\hline & $<60$ & 3 \\
\hline & $60-69$ & 13 \\
\hline & $70-79$ & 28 \\
\hline & $80-89$ & 13 \\
\hline & $\geq 90$ & 3 \\
\hline Jex & Male & 34 \\
\hline \multicolumn{3}{|c|}{ Primary site } \\
\hline & Genital & 54 \\
\hline & tal and axillary & 1 \\
\hline & axillary, and navel & 1 \\
\hline & Perianal & 2 \\
\hline & Axillary & 1 \\
\hline \multirow{2}{*}{\multicolumn{3}{|c|}{ Clinical manifestations }} \\
\hline & & \\
\hline & Nodule & 9 \\
\hline & Erosion & 33 \\
\hline \multirow{2}{*}{\multicolumn{3}{|c|}{$\begin{array}{l}\text { Depigmentation } \\
\text { Dermal invasion }\end{array}$}} \\
\hline & & \\
\hline & Absent & 44 \\
\hline & Present & 16 \\
\hline \multicolumn{3}{|c|}{ Lymph node metastases } \\
\hline & Absent & 52 \\
\hline & Present & 8 \\
\hline
\end{tabular}

Table 2. Difference in clinical characteristics in dermcidin expression.

\begin{tabular}{|c|c|c|c|c|}
\hline Variable & Total & Dermcidin (+) & Dermcidin (-) & $p$ Value \\
\hline Total & 60 & 14 & 46 & \multirow{2}{*}{0.314} \\
\hline$<70$ & 16 & 2 & 14 & \\
\hline$\geq 70$ & 44 & 12 & 32 & \multirow{2}{*}{1.000} \\
\hline Male & 34 & 8 & 26 & \\
\hline \multirow{2}{*}{ Nodule } & 26 & 6 & 20 & \multirow{2}{*}{0.003} \\
\hline & 51 & 8 & 43 & \\
\hline \multirow{2}{*}{ Erosion } & 9 & 6 & 3 & \multirow{2}{*}{0.013} \\
\hline & 27 & 2 & 25 & \\
\hline Present & 33 & 12 & 21 & \multirow{3}{*}{1.000} \\
\hline Depigmentation & & & & \\
\hline Absent & 39 & 9 & 30 & \\
\hline Present & 21 & 5 & 16 & \multirow{3}{*}{0.006} \\
\hline Dermal invasion & & & & \\
\hline Absent & 44 & 6 & 38 & \\
\hline Present & 16 & 8 & 8 & \multirow{4}{*}{0.013} \\
\hline Lymph node metastases & & & & \\
\hline Absent & 52 & 9 & 43 & \\
\hline Present & 8 & 5 & 3 & \\
\hline
\end{tabular}

\subsection{The Different Prognosis in Extramammary Paget's Disease}

We next investigated the prognostic impact of dermcidin in extramammary Paget's disease. The mean survival times were different between positive and negative dermcidin expression in the tumor. Kaplan-Meier curves of overall survival are shown in Figure 3. The overall survival rate in dermcidin-positive patients was significantly lower than that in dermcidin-negative patients. Therefore, a high expression of dermcidin is associated with the poorest prognosis.

Finally, we conducted univariate analyses of dermcidin expression in comparison with clinical variables (Table 3). Univariate analysis showed significantly increased hazard ratios in nodules upon physical examination and dermal invasion and lymph node metastasis 
in the histological examination, consistent with previous studies $[4,19]$. In addition, a high expression of dermcidin leads to a significantly increased hazard ratio. Although the impact of dermcidin on prognosis might be limited, dermcidin might become a tool for estimating prognosis in patients with extramammary Paget's disease in some cases.

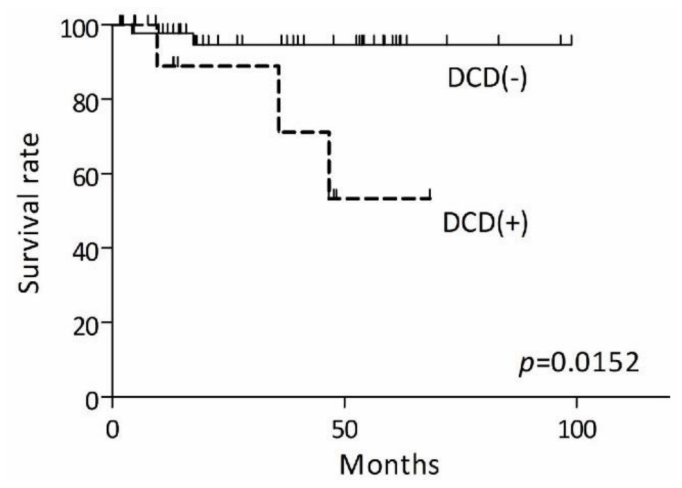

Figure 3. Differences in overall survival curve with or without dermcidin expression in extramammary Paget's disease. The overall survival curves were drawn using the Kaplan-Meier method and were compared with the log-rank test.

Table 3. Univariate analysis of clinical variables.

\begin{tabular}{|c|c|c|c|c|}
\hline Variable & & HR & $95 \%$ CI & $p$ Value \\
\hline \multirow[t]{3}{*}{ Age } & & & & 0.234 \\
\hline & $<70$ & 1 & & \\
\hline & $\geq 70$ & 0.3262 & $0.05144-2.068$ & \\
\hline \multirow[t]{3}{*}{ Sex } & & & & 0.709 \\
\hline & Male & 1 & & \\
\hline & Female & 1.398 & $0.2406-8.117$ & \\
\hline \multirow[t]{3}{*}{ Nodule } & & & & $<0.0001$ \\
\hline & Absent & 1 & & \\
\hline & Present & 7561 & $338.7-168,800$ & \\
\hline \multirow[t]{3}{*}{ Erosion } & & & & 0.275 \\
\hline & Absent & 1 & & \\
\hline & Present & 2.671 & $0.4570-15.60$ & \\
\hline \multirow[t]{3}{*}{ Depigmentation } & & & & 0.432 \\
\hline & Absent & 1 & & \\
\hline & Present & 0.4823 & $0.07834-2.969$ & \\
\hline \multirow[t]{3}{*}{ Dermal invasion } & & & & $<0.0001$ \\
\hline & Absent & 1 & & \\
\hline & Present & 240.8 & $24.80-2338$ & \\
\hline \multirow[t]{3}{*}{ Lymph node metastases } & & & & $<0.0001$ \\
\hline & Absent & 1 & & \\
\hline & Present & 442,600 & $\begin{array}{c}16,480- \\
11,880,000\end{array}$ & \\
\hline \multirow[t]{3}{*}{ dermcidin expression } & & & & 0.015 \\
\hline & Absent & 1 & & \\
\hline & Present & 16.79 & $1.721-163.7$ & \\
\hline
\end{tabular}

\section{Discussion}

This study revealed that positive dermcidin expression reflects unfavorable clinical behavior in extramammary Paget's cell tumors. Cancer cell migration into lymph nodes is an important step in the progression toward the advanced stage of malignant tumors. However, the detailed molecular mechanism determining whether dermcidin promotes such tumor cell migration remains unclear.

Our study showed that dermcidin-positive extramammary Page's disease exhibited a high frequency of nodules upon physical examination. One of the reasons behind this 
might be that dermcidin contributes to the development of the tumor. High dermcidin expression is associated with tumor growth in gastric [20] and breast cancer [21]. Interestingly, dermcidin is also associated with tumor growth and tumor apoptosis in breast cancer. As regards the mechanisms, dermcidin has been found to modulate the HER-2-mediated signal pathway [21], which is one of the major pathways in breast cancer [22]. Because HER-2 signaling is also involved in the pathogenesis of extramammary Paget's disease [23], it is assumed that dermcidin might also activate HER-2 signaling in extramammary Paget's disease and subsequently lead to the development of tumor growth. Because there was no commercially available cell line of extramammary Paget's disease, however, further investigation will be required to clarify the detailed molecular mechanisms.

Several studies have already shown the potential of dermcidin as a biomarker for malignancies. A high expression of dermcidin was identified in approximately $10 \%$ of breast cancer patients and has been found to be closely associated with the advanced clinical stage and unfavorable clinical behavior due to regulation of tumor cell growth [24]. Serum dermcidin levels were significantly increased in hepatocellular carcinoma patients and were positively correlated with metastasis [25]. Dermcidin expression in gastric cancer reflects overall survival and is positively correlated with lymph node metastasis [20]. Dermcidin expression is higher in lung cancer patients compared with that in healthy subjects [26]. Among cutaneous malignancies, having high serum levels of dermcidin at the moment of melanoma diagnosis has been associated with the metastatic progression of melanoma among melanoma patients [27,28].

Dermcidin has also been reported as a biomarker in various diseases in addition to malignant tumors. Dermcidin has been identified as a biomarker for Alzheimer's disease (AD) [29], asthma [30], acne vulgaris [31,32], severe obstructive sleep apnea [33], and facioscapulohumeral muscular dystrophy [34]. For example, an abundance of dermcidin was identified in exhaled breath condensate in asthma patients [30]. Therefore, dermcidin may also be a potential biomarker in a variety of skin diseases.

The reason that positive dermcidin expression was observed in clinical patients with unfavorable outcomes who suffered from extramammary Paget's disease remains unclear. A previous study suggested the possibility that one of the characteristics of the eccrine glands might be linked to extramammary Paget's disease. The expressions of histoblood group A type 1,2, and 3 antigens in normal human skin and extramammary Paget's disease were examined via the immunohistochemical technique [35]. The eccrine glands expressed these antigens, while a negative expression of these antigens was observed in apocrine glands, suggesting that extramammary Paget's disease might be an apocrinegland-derived tumor stemming from a negative reaction to these antigens. However, 7 out of 16 cases were positive for these antigens, and 6 out of 7 positive cases were associated with dermal invasion. Meanwhile, 5 cases without dermal invasion were negative against these antigens. Although there has been a limited number of studies focusing on this issue to date, the possibility still exists that eccrine gland characteristics include the development of extramammary Paget's disease.

A previous study showed a negative dermcidin expression in patients with extramammary Paget's disease [18]. However, we speculated that the reason behind this result might be that this study did not include any unfavorable clinical cases to show a representative tumor phenotype of extramammary Paget's disease, which is generally located in the epidermis. This previous study may have selected noninvasive extramammary Paget's disease samples to visualize a representative sample of an indolent cutaneous tumor from an extramammary Paget's disease patient.

One possible limitation of our study was that the number of patients involved might not be sufficient to investigate the more detailed characteristics of dermcidin-positive patients with extramammary Paget's disease. Additionally, the detailed molecular role of dermcidin in extramammary Paget's disease for the invasion and metastasis of tumors still needs to be clarified, especially how the degree of dermcidin is associated with the acti- 
vation of metastatic factors and tumor development, which are involved in the molecular mechanism mediated by HER-2 signaling.

The reason that many of the censored cases are in the dermcidin-negative survival curve may be related to the characteristics of indolent-type cutaneous malignancy. Patients with the nondermal invasion type had their clinical observation follow-up in other hospitals after surgical resection in our department. By contrast, dermal invasion cases are known to have an unfavorable clinical behavior, as shown in Figure 2, and thus, careful follow-up was needed in our hospital or in another hospital where skin oncologists are available.

In conclusion, dermcidin has the potential to help toward the prognosis of extramammary Paget's disease at the moment of surgical resection of the tumor. It is therefore urgently needed to further investigate the actual impact of dermcidin on the molecular mechanism of the development of extramammary Paget's disease.

Author Contributions: S.O. and Y.S. designed, analyzed, and wrote the manuscript. N.S.-S., S.S., Y.M., H.S., H.N., K.Y., and E.O. were extramammary Paget's disease patients treated at our hospital and enrolled in this study who conducted a critical review of this manuscript. M.N. organized this study and wrote the manuscript. All authors have read and agreed to the published version of the manuscript.

Funding: This research received no external funding.

Institutional Review Board Statement: This study was conducted with the approval of and in accordance with the guidelines of the Ethics Committee of the University of Occupational and Environmental Health (approved code H29-211, approved date 20 November 2017), and in accordance with the Declaration of Helsinki. This study was conducted using the opt-out method of obtaining a waiver of informed consent, which was adopted with the Ethics Committee's approval.

Informed Consent Statement: Because this study was a retrospective cohort study, the opt-out method of obtaining informed consent was adopted, and informed consent was waived by the In-stitutional Review Board at the University of Occupational and Environmental Health.

Data Availability Statement: Not applicable.

Conflicts of Interest: This research was conducted in the absence of any commercial or financial relationships that could be construed as a potential conflict of interest.

\section{References}

1. Dainichi, T.; Kitoh, A.; Otsuka, A.; Nakajima, S.; Nomura, T.; Kaplan, D.H.; Kabashima, K. The epithelial immune microenvironment (EIME) in atopic dermatitis and psoriasis. Nat. Immunol. 2018, 19, 1286-1298. [CrossRef] [PubMed]

2. Kabashima, K.; Honda, T.; Ginhoux, F.; Egawa, G. The immunological anatomy of the skin. Nat. Rev. Immunol. 2019, 19, 19-30. [CrossRef] [PubMed]

3. Sawada, Y.; Gallo, R.L. Role of Epigenetics in the Regulation of Immune Functions of the Skin. J. Investig. Dermatol. 2021, 141, 1157-1166. [CrossRef] [PubMed]

4. Morris, C.R.; Hurst, E.A. Extramammary Paget's Disease: A Review of the Literature Part II: Treatment and Prognosis. Dermatol. Surg. 2020, 46, 305-311. [CrossRef]

5. Galloway, T.J.; Ridge, J.A. Management of Squamous Cancer Metastatic to Cervical Nodes With an Unknown Primary Site. J. Clin. Oncol. 2015, 33, 3328-3337. [CrossRef]

6. Tarhini, A.A. The current state of adjuvant therapy of melanoma. Lancet Oncol. 2020, 21, 1394-1395. [CrossRef]

7. Sawada, Y.; Bito, T.; Kabashima, R.; Yoshiki, R.; Hino, R.; Nakamura, M.; Shiraishi, M.; Tokura, Y. Ectopic extramammary Paget's disease: Case report and literature review. Acta Derm. Venereol. 2010, 90, 502-505. [CrossRef]

8. Mazoujian, G.; Pinkus, G.S.; Haagensen, D.E., Jr. Extramammary Paget's disease-evidence for an apocrine origin. An immunoperoxidase study of gross cystic disease fluid protein-15, carcinoembryonic antigen, and keratin proteins. Am. J. Surg. Pathol. 1984, 8, 43-50. [CrossRef]

9. Hatta, N.; Yamada, M.; Hirano, T.; Fujimoto, A.; Morita, R. Extramammary Paget's disease: Treatment, prognostic factors and outcome in 76 patients. Br. J. Dermatol. 2008, 158, 313-318. [CrossRef]

10. Ito, Y.; Igawa, S.; Ohishi, Y.; Uehara, J.; Yamamoto, A.I.; Iizuka, H. Prognostic indicators in 35 patients with extramammary Paget's disease. Dermatol. Surg. 2012, 38, 1938-1944. [CrossRef]

11. van der Zwan, J.M.; Siesling, S.; Blokx, W.A.; Pierie, J.P.; Capocaccia, R. Invasive extramammary Paget's disease and the risk for secondary tumours in Europe. Eur. J. Surg. Oncol. 2012, 38, 214-221. [CrossRef] 
12. Jones, R.E., Jr.; Austin, C.; Ackerman, A.B. Extramammary Paget's disease. A critical reexamination. Am. J. Dermatopathol. 1979, 1, 101-132. [CrossRef]

13. Schittek, B.; Hipfel, R.; Sauer, B.; Bauer, J.; Kalbacher, H.; Stevanovic, S.; Schirle, M.; Schroeder, K.; Blin, N.; Meier, F.; et al. Dermcidin: A novel human antibiotic peptide secreted by sweat glands. Nat. Immunol. 2001, 2, 1133-1137. [CrossRef]

14. Dellino, M.; Gargano, G.; Tinelli, R.; Carriero, C.; Minoia, C.; Tetania, S.; Silvestris, E.; Loizzi, V.; Paradiso, A.; Casamassima, P.; et al. A strengthening the reporting of observational studies in epidemiology (STROBE): Are HE4 and CA 125 suitable to detect a Paget disease of the vulva? Medicine 2021, 100, e24485. [CrossRef]

15. Saito-Sasaki, N.; Sawada, Y.; Okada, E.; Nakamura, M. Cell Adhesion Molecule 1 (CADM1) Is an Independent Prognostic Factor in Patients with Cutaneous Squamous Cell Carcinoma. Diagnostics 2021, 11, 830. [CrossRef]

16. Mashima, E.; Sawada, Y.; Yamaguchi, T.; Yoshioka, H.; Ohmori, S.; Haruyama, S.; Yoshioka, M.; Okada, E.; Nakamura, M. A high expression of cell adhesion molecule 1 (CADM1) is an unfavorable prognostic factor in mycosis fungoides. Clin. Immunol. 2018, 193, 121-122. [CrossRef]

17. She, X.; Rohl, C.A.; Castle, J.C.; Kulkarni, A.V.; Johnson, J.M.; Chen, R. Definition, conservation and epigenetics of housekeeping and tissue-enriched genes. BMC Genom. 2009, 10, 269. [CrossRef]

18. Minami, Y.; Uede, K.; Sagawa, K.; Kimura, A.; Tsuji, T.; Furukawa, F. Immunohistochemical staining of cutaneous tumours with G-81, a monoclonal antibody to dermcidin. Br. J. Dermatol. 2004, 151, 165-169. [CrossRef]

19. Ito, T.; Kaku, Y.; Nagae, K.; Nakano-Nakamura, M.; Nakahara, T.; Oda, Y.; Hagihara, A.; Furue, M.; Uchi, H. Tumor thickness as a prognostic factor in extramammary Paget's disease. J. Dermatol. 2015, 42, 269-275. [CrossRef]

20. Zhang, J.; Ding, W.; Kuai, X.; Ji, Y.; Zhu, Z.; Mao, Z.; Wang, Z. Dermcidin as a novel binding protein of lncRNA STCAT3 and its effect on prognosis in gastric cancer. Oncol. Rep. 2018, 40, 2854-2863. [CrossRef]

21. Bancovik, J.; Moreira, D.F.; Carrasco, D.; Yao, J.; Porter, D.; Moura, R.; Camargo, A.; Fontes-Oliveira, C.C.; Malpartida, M.G.; Carambula, S.; et al. Dermcidin exerts its oncogenic effects in breast cancer via modulation of ERBB signaling. BMC Cancer 2015, 15, 70. [CrossRef]

22. Slamon, D.J.; Clark, G.M.; Wong, S.G.; Levin, W.J.; Ullrich, A.; McGuire, W.L. Human breast cancer: Correlation of relapse and survival with amplification of the HER-2/neu oncogene. Science 1987, 235, 177-182. [CrossRef]

23. Tanskanen, M.; Jahkola, T.; Asko-Seljavaara, S.; Jalkanen, J.; Isola, J. HER2 oncogene amplification in extramammary Paget's disease. Histopathology 2003, 42, 575-579. [CrossRef]

24. Porter, D.; Weremowicz, S.; Chin, K.; Seth, P.; Keshaviah, A.; Lahti-Domenici, J.; Bae, Y.K.; Monitto, C.L.; Merlos-Suarez, A.; Chan, J.; et al. A neural survival factor is a candidate oncogene in breast cancer. Proc. Natl. Acad. Sci. USA 2003, 100, 10931-10936. [CrossRef]

25. Qiu, F.; Qiu, F.; Liu, L.; Liu, J.; Xu, J.; Huang, X. The Role of Dermcidin in the Diagnosis and Staging of Hepatocellular Carcinoma. Genet. Test. Mol. Biomark. 2018, 22, 218-223. [CrossRef]

26. Núñez-Naveira, L.; Mariñas-Pardo, L.A.; Montero-Martínez, C. Mass Spectrometry Analysis of the Exhaled Breath Condensate and Proposal of Dermcidin and S100A9 as Possible Markers for Lung Cancer Prognosis. Lung 2019, 197, 523-531. [CrossRef]

27. Mancuso, F.; Lage, S.; Rasero, J.; Díaz-Ramón, J.L.; Apraiz, A.; Pérez-Yarza, G.; Ezkurra, P.A.; Penas, C.; Sánchez-Diez, A.; García-Vazquez, M.D.; et al. Serum markers improve current prediction of metastasis development in early-stage melanoma patients: A machine learning-based study. Mol. Oncol. 2020, 14, 1705-1718. [CrossRef]

28. Ortega-Martínez, I.; Gardeazabal, J.; Erramuzpe, A.; Sanchez-Diez, A.; Cortés, J.; García-Vázquez, M.D.; Pérez-Yarza, G.; Izu, R.; Luís Díaz-Ramón, J.; de la Fuente, I.M.; et al. Vitronectin and dermcidin serum levels predict the metastatic progression of AJCC I-II early-stage melanoma. Int. J. Cancer 2016, 139, 1598-1607. [CrossRef]

29. Kang, S.; Jeong, H.; Baek, J.H.; Lee, S.J.; Han, S.H.; Cho, H.J.; Kim, H.; Hong, H.S.; Kim, Y.H.; Yi, E.C.; et al. PiB-PET Imaging-Based Serum Proteome Profiles Predict Mild Cognitive Impairment and Alzheimer's Disease. J. Alzheimer's Dis. 2016, 53, 1563-1576. [CrossRef]

30. Bloemen, K.; Van Den Heuvel, R.; Govarts, E.; Hooyberghs, J.; Nelen, V.; Witters, E.; Desager, K.; Schoeters, G. A new approach to study exhaled proteins as potential biomarkers for asthma. Clin. Exp. Allergy 2011, 41, 346-356. [CrossRef]

31. Alatas, E.T.; Kara Polat, A.; Kalayci, M.; Dogan, G.; Akin Belli, A. Plasma dermcidin levels in acne patients, and the effect of isotretinoin treatment on dermcidin levels. Dermatol. Ther. 2019, 32, e13044. [CrossRef] [PubMed]

32. El Aziz Ragab, M.A.; Omar, S.S.; Collier, A.; El-Wafa, R.; Gomaa, N. The effect of continuous high versus low dose oral isotretinoin regimens on dermcidin expression in patients with moderate to severe acne vulgaris. Dermatol. Ther. 2018, 31, e12715. [CrossRef] [PubMed]

33. Kohli, M.; Sharma, S.K.; Upadhyay, V.; Varshney, S.; Sengupta, S.; Basak, T.; Sreenivas, V. Urinary EPCR and dermcidin as potential novel biomarkers for severe adult OSA patients. Sleep Med. 2019, 64, 92-100. [CrossRef] [PubMed]

34. Corasolla Carregari, V.; Monforte, M.; Di Maio, G.; Pieroni, L.; Urbani, A.; Ricci, E.; Tasca, G. Proteomics of Muscle Microdialysates Identifies Potential Circulating Biomarkers in Facioscapulohumeral Muscular Dystrophy. Int. J. Mol. Sci. 2020, 22, 290. [CrossRef]

35. Tanaka, A.; Kimura, A.; Yamamoto, Y.; Uede, K.; Furukawa, F. Expression of histo-blood group A type 1, 2 and 3 antigens in normal skin and extramammary Paget's disease. Acta Histochem. Cytochem. 2008, 41, 165-171. [CrossRef] 